\title{
PENGARUH GREEN PERCEIVED VALUE, GREEN PERCEIVED RISK, GREEN \\ CONSUMER CONSFUSION, GREEN TRUST, CONSUMER GUILT, SELF \\ MONITORING, PRIDE DAN PERCEIVED CONSUMER EFFECTIVENESS \\ TERHADAP GREEN PURCHASE INTENTION \\ (KASUS STARBUCKS JAKARTA)
}

\author{
Feliks Antonius \\ Program Studi Magister Manajemen Universitas Tarumanagara \\ feliksantonius@gmail.com
}

\begin{abstract}
The research aims to find out the relationship between green perceived value, green perceived risk, green consumer consfusion, green trust, consumer guilt, self monitoring, pride and perceived consumer effectiveness to green purchase intention in Starbucks Jakarta. The method used in sampling is non-probability sampling method with purposive sampling technique which is a sampling technique by selecting sampling unit on the basis of certain criteria. The period of questionaire taking starts in May-September 2017. The data obtained will be analyze using Structural Equation Modeling (SEM). The conclusion of this study indicates green perceived value and green perceived risk have significant influence to green trust. Consumer guilt, self monitoring and pride have significant effect to perceived consumer effectiveness on product Starbucks. Green trust and perceived consumer effectiveness as intervening variable at significance $5 \%$. More specifically, the effect of green consumer confusion on green trust is not significant and the effect of green trust on green purchase intention is not significant too. The sum of increasing perceived consumer effectiveness then increasing green purchase intention.
\end{abstract}

Keywords : green perceived value, green perceived risk, green consumer confusion, green trust, consumer guilt, self monitoring, pride, perceived consumer effectiveness, green purchase intention

\section{PENDAHULUAN}

Kepedulian akan lingkungan telah mendapat perhatian yang lebih besar dalam beberapa tahun terakhir ini. Sebenarnya, perubahan yang dilakukan manusia terhadap lingkungan sudah dilakukan sejak lama. Namun, untuk menghindari kerusakan lebih lanjut terhadap lingkungan, tercipta konsep green (hijau) dan sekarang ini sudah berkembang. Setiap individu, perusahaan bisnis, lembaga dan pemerintah telah terus-menerus mengambil berbagai langkah inisiatif agar terlihat hijau. Kegiatan ini juga disebut sebagai sustainable/environmental friendly/eco-friendly efforts (ramah lingkungan) (Vaishnavi, Ganesh \& Thomas, 2014).

Polonsky (Wu Chen, 2014) mendefinisikan green marketing sebagai semua kegiatan yang dirancang oleh perusahaan dalam rangka memenuhi kebutuhan. manusia dengan mengurangi dampak yang merugikan bagi lingkungannya. Menurut Petiete (Chen, 2012) green marketing tidak hanya dapat memberikan strategi diferensiasi dengan menciptakan kebutuhan lingkungan, tetapi juga membentuk kembali aturan pemasaran di pasar. Sejak masyarakat lebih bersedia untuk membeli produk hijau dengan informasi yang dapat dipercaya, perusahaan harus menyediakan informasi yang dapat dipercaya bagi konsumen mereka untuk mengurangi risiko yang dirasakan pelanggan.

\section{PEMBATASAN MASALAH}

Dengan melihat semakin banyaknya konsumen yang sadar terhadap betapa pentingnya menjaga kelestarian lingkungan dan semakin banyaknya produsen yang menerapkan strategi 
green marketing, penulis tertarik untuk meneliti faktor-faktor apa saja yang mempengaruhi green purchase intention pada produk Starbucks. Karena adanya keterbatasan waktu, data, dan ruang lingkup permasalahan, maka penelitian ini dibatasi dan akan membahas pengaruh Green Perceived Value, Green Perceived Risk, Green Trust, Consumer Guilt, Self Monitoring, Pride dan Perceived Consumer Effectiveness terhadap Green Purchase Intention (Kasus Starbucks Jakarta).

\section{DEFINISI VARIABEL}

Green perceived value menurut Chen \& Chang (2012) green perceived value artinya penilaian secara umum dari konsumen tentang keuntungan dari barang atau jasa yang memiliki manfaat bagi lingkungan sesuai dengan apa yang diharapkan konsumen (Chen \& Chang, 2012).

Green perceived risk adalah suatu persepsi yang timbul dari konsekuensi lingkungan negatif terkait dengan perilaku pembelian (Cen \&Chang, 2012).

Green consumer confusion adalah kegagalan konsumen untuk memperbaiki interpretasi baik terhadap produk atau layanan yang ramah lingkungan selama penyampaian informasi tersebut (Cen \& Chang, 2012).

Green trust sendiri adalah kesediaan menggunakan beberapa produk, layanan, atau merek tertentu yang diyakini memiliki dampak positif pada lingkungan (Chen \& Chang, 2012) .

Consumer guilt menurut Watson dan Spene, consumer guilt adalah jenis rasa bersalah yang khusus berkaitan dengan situasi keputusan konsumsi. Perasaan bersalah berbeda dari konsep bersalah (Dedeoglu, et.al, 2010).

Self monitoring adalah sebuah psikologi sosial yang terbentuk berdasarkan pengamatan diri dan kontrol diri untuk menyadari tanda yang ada terkait perilaku sosial dalam keadaan tertentu (Kabadayi, et.al, 2015).

Pride adalah sebuah emosi positif terkait dengan pencapaian dan nilai diri (Antonetti \& Maklan, 2013).

Perceived consumer effectiveness adalah kemampuan untuk mengambil keputusan dari hasil kepercayaan terhadap efektivitas pilihan konsumen secara umum (Kabadayi, et.al, 2015).

Green purchase intention adalah kemungkinan konsumen untuk membeli sebuah produk yang ramah lingkungan sesuai dengan kebutuhannya (Kabadayi, et.al, 2015).

\section{TELAAH KEPUSTAKAAN}

Penelitian Enhance green purchase intentions The roles of green perceived value, green perceived risk, and green trust oleh $\mathrm{Yu}$-Shan Chen dan Ching-Hsun Chang membahas pengaruh green perceived value, green perceived risk, dan green trust terhadap green purchase intention. Hasil penelitian adalah green perceived value, green perceived risk, dan green trust berpengaruh positif terhadap green purchase intention.

Penelitian Green purchase intention of young Turkish consumers: Effects of consumer's guilt, self-monitoring and perceived consumer effectiveness oleh Ebru Tümer Kabadayı, İnci Dursunb , Alev Koçak Alana dan Ahmet Tuğrul Tuğera membahas pengaruh consumer's guilt, self-monitoring dan perceived consumer effectiveness terhadap green purchase intention. Hasilnya consumer's guilt, self-monitoring berpengaruh positif terhadap perceived consumer effectiveness, sedangkan consumer's guilt dan perceived consumer effectiveness berpengaruh terhadap green purchase intention.

Penelitian Feelings that Make a Difference: How Guilt and Pride Convince Consumers of the Effectiveness of Sustainable Consumption Choices oleh Paolo Antonetti dan Stan Maklan membahas pengaruh guilt dan pride terhadap purchase customer effectiveness dan pengaruh purchase customer effectiveness terhadap purchase intention. Hasil penelitian menunjukkan 
pengaruh positif dari guilt dan pride terhadap perceived customer effectiveness dan pengaruh positif perceived customer effectiveness terhadap purchase intention.

Penelitian Greenwash and Green Trust: The Mediation Effects of Green Consumer Confusion and Green Perceived Risk oleh Yu-Shan Chen dan Ching-Hsun Chang membahas pengaruh green consumer confusion, green perceived risk dan greenwash terhadap green trust. Hasil green consumer confusion, green perceived risk dan greenwash menunjukkan pengaruh negatif terhadap green trust.

\section{METODE PEMILIHAN DATA}

Metode pemillihan data yang digunakan adalah dengan kuesioner. Bentuk pertanyaan pada kuesioner penelitian ini adalah pertanyaan tertutup (closed-ended question). Ini merupakan suatu bentuk pertanyaan dimana responden akan diminta untuk memilih salah satu dari jawaban alternatif yang telah disediakan. Metode yang digunakan dengan skala Likert.

\section{METODE PENELITIAN}

Berdasarkan teori yang telah diiuraikan sebelumnya, maka akan diuji apakah green perceived value, green perceived risk, green consumer confusion, consumer guilt, self monitoring, pride, green trust dan perceived consumer effectiveness terhadap green purchase intention, maka terdapat model penelitian sebagai berikut :

Gambar 1.1 Model Penelitian

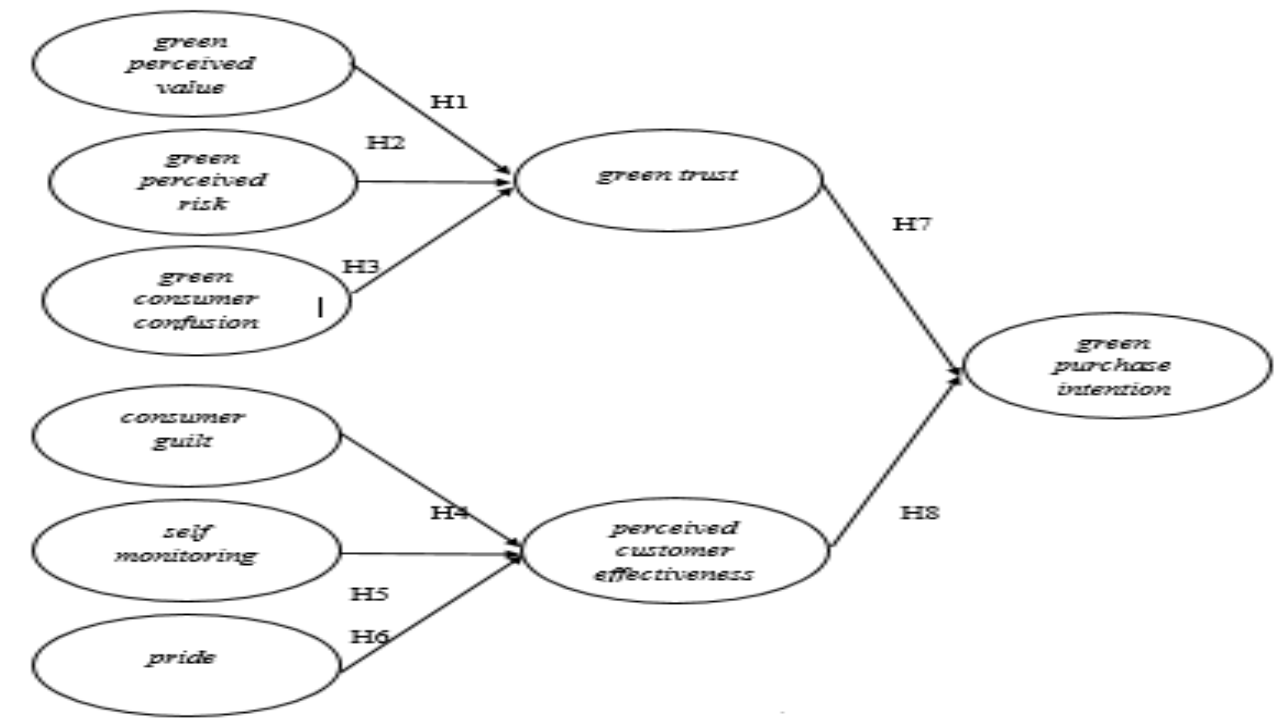

Metode analisis yang digunakann adalah metode analisis structural equation modeling (SEM) atau model persamaan struktural. Metode analisis SEM ini merupakan perkembangan dari beberapa keterbatasan analisis multivariat.

\section{HIPOTESIS}

$\mathrm{H} 1$ : green perceived value berpengaruh terhadap green trust

$\mathrm{H} 2$ : green perceived risk berpengaruh negatif terhadap green trust

$\mathrm{H} 3$ : green consumer confusion berpengaruh negatif terhadap green trust

$\mathrm{H} 4$ : consumer guilt berpengaruh positif terhadap perceived customer effectiveness

H5 : self monitoring berpengaruh positif terhadap perceived customer effectiveness

H6 : pride berpengaruh positif terhadap perceived customer effectiveness

$\mathrm{H} 7$ : green trust berpengaruh positif terhadap green purchase intention

H8 : perceived consumer effectiveness berpengaruh positif terhadap green purchase intention 
Gambar

Model SEM dengan Path Analysis Setelah Modifikasi

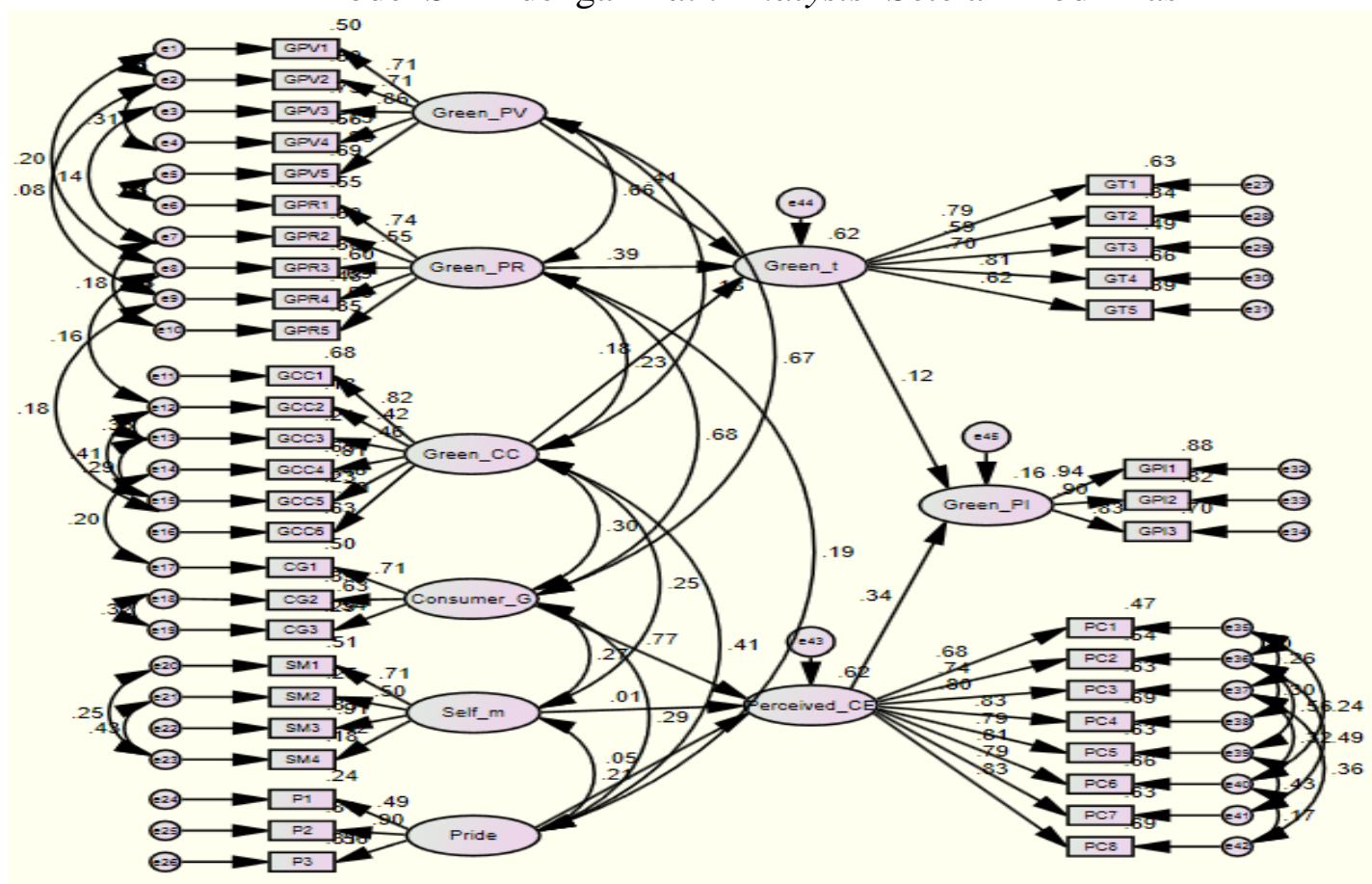

ANALISIS DAN BAHASAN TEMUAN

\begin{tabular}{|c|c|c|c|cc|}
\hline Hipotesa & Hubungan & $\begin{array}{c}\mathbf{t} \\
\text { hitung }\end{array}$ & Sig & Keputusan & Kesimpulan \\
\hline H1 & Green_PV --> Green t & 5,696 & 0,000 & Tolak H0 & Mendukung H1 \\
\hline H2 & Green_PR --> Green t & 4,747 & 0,007 & Tolak H0 & Mendukung H2 \\
\hline H3 & Green_CC --> Green t & 3,616 & 0,247 & Terima H0 & $\begin{array}{c}\text { Tidak mendukung } \\
\text { H3 }\end{array}$ \\
\hline H4 & $\begin{array}{c}\text { Consumer_G --> } \\
\text { Perceived_CE }\end{array}$ & 7,432 & 0,000 & Tolak H0 & Mendukung H4 \\
\hline H5 & Self_m --> Perceived_CE & 0,092 & 0,000 & Tolak H0 & Mendukung H5 \\
\hline H6 & Pride --> Perceived_CE & 0,895 & 0,021 & Tolak H0 & Mendukung H6 \\
\hline H7 & Green_t --> Green_PI & 1,828 & 0,226 & Terima H0 & $\begin{array}{c}\text { Tidak mendukung } \\
\text { H7 }\end{array}$ \\
\hline H8 & Perceived_CE --> Green_PI & 4,981 & 0,000 & Tolak H0 & Mendukung H8 \\
\hline
\end{tabular}

\section{$\mathrm{H}_{1}$ : Green Perceived Value berpengaruh terhadap Green Trust}

Nilai sig pada uji hipotesa Green Perceived Value terhadap Green Trust adalah sebesar 0,000. Karena nilai sig nya $(0,000)<0,05$ maka tolak $\mathrm{H}_{0}$ dan mendukung $\mathrm{H}_{1}$. Maka untuk meningkatkan green trust dapat dilakukan dengan menaikkan green perceived value itu sendiri

\section{H2 : Green Perceived Risk berpengaruh terhadap Green Trust}

Nilai sig pada uji hipotesa Green Perceived Risk terhadap Green Trust adalah sebesar 0,007 . Karena nilai sig nya $(0,007)<0,05$ maka tolak $\mathrm{H}_{0}$ dan mendukung $\mathrm{H}_{2}$. Sebagai kesimpulannya Green Perceived Risk berpengaruh signifikan terhadap Green Trust.

\section{H3 : Green Consumer Confusion tidak berpengaruh terhadap Green Trust}

Nilai sig pada uji hipotesa Green Consumer Confusion terhadap Green Trust adalah sebesar 0247. Karena nilai sig nya $(0,247)>0,05$ maka terima $\mathrm{H}_{0}$ dan tidak mendukung $\mathrm{H}_{3}$. 
Sebagai kesimpulannya Green Consumer Confusion tidak berpengaruh signifikan terhadap Green Trust.

\section{H4 : consumer guilt berpengaruh terhadap perceived customer effectiveness}

Nilai sig pada uji hipotesa Consumer Guilt terhadap Perceived Consumer Effectiveness adalah sebesar 0,000. Karena nilai sig nya $(0,000)<0,05$ maka tolak $\mathrm{H}_{0}$ dan mendukung $\mathrm{H}_{4}$. Sebagai kesimpulannya Consumer Guilt berpengaruh signifikan terhadap Perceived Consumer Effectiveness.

\section{H5 : self monitoring berpengaruh positif terhadap perceived customer effectiveness}

Nilai sig pada uji hipotesa Self Monitoring terhadap Perceived Consumer Effectiveness adalah sebesar 0,000. Karena nilai sig nya $(0,000)<0,05$ maka tolak $\mathrm{H}_{0}$ dan mendukung $\mathrm{H}_{5}$. Sebagai kesimpulannya Self Monitoring berpengaruh signifikan terhadap Perceived Consumer Effectiveness.

\section{H6 : pride berpengaruh positif terhadap perceived customer effectiveness}

Nilai sig pada uji hipotesa Pride terhadap Perceived Consumer Effectiveness adalah sebesar 0,021. Karena nilai sig nya $(0,021)<0,05$ maka tolak $\mathrm{H}_{0}$ dan mendukung $\mathrm{H}_{6}$. Sebagai kesimpulannya Pride berpengaruh signifikan terhadap Perceived Consumer Effectiveness.

\section{H7 : green trust berpengaruh positif terhadap green purchase intention}

Nilai sig pada uji hipotesa Green Trust terhadap Green_PI adalah sebesar 0,226. Karena nilai sig nya $(0,226)>0,05$ maka terima $\mathrm{H}_{0}$ dan tidak mendukung $\mathrm{H}_{7}$. Sebagai kesimpulannya Green Trust tidak berpengaruh signifikan terhadap Green Purchase Intention.

\section{H8 : perceived consumer effectiveness berpengaruh positif terhadap green purchase intention}

Nilai sig pada uji hipotesa Perceived Consumer Effectiveness terhadap Green Purchase Intention adalah sebesar 0,000 . Karena nilai sig nya $(0,000)<0,05$ maka $\mathrm{H}_{1}$ diterima. Sebagai kesimpulannya Perceived Consumer Effectiveness berpengaruh signifikan terhadap Green Purchase Intention.

\section{Penutup}

Kesimpulan Hasil yang dapat diambil dalam penelitian ini : (1)Green perceived value berpengaruh signifikan terhadap green trust. (2) Green perceived risk berpengaruh signifikan terhadap green trust. (3) Green consumer confusion tidak berpengaruh signifikan terhadap green trust.(4) Consumer guilt berpengaruh signifikan terhadap perceived consumer effectiveness. (5) Self monitoring berpengaruh signifikan terhadap perceived consumer effectivenes. (6) Pride berpengaruh signifikan terhadap perceived consumer effectivenes. (7) Green trust tidak berpengaruh signifikan terhadap green purchase intention. (8) Perceived consumer effectiveness berpengaruh signifikan terhadap green purchase intention. (9) Green perceived value dann green perceived risk simultan berpengaruh positif dan signifikan terhadap green trust. (10) Consumer guilt, self monitoring dan pride simultan berpengaruh positif dan signifikan terhadap perceived consumer effectiveness.

Saran (1) Memberikan informasi yang lebih lengkap mengenai kualitas bahan ramah lingkungan yang digunakan pada kemasan ataupun poster dan informasi secara digital agar nilai green perceived value Starbucks semakin tinggi dimata masyarakat sehingga nilai green trust Starbucks dapat semakin tinggi. (2) Mengadakan kegiatan seperti kampanye ramah 
lingkungan dari Starbucks secara rutin atau kegiatan diskon jika menggunakan botol dalam kemasan yang ramah lingkungan dapat menurunkan persepsi negatif terkait pembelian produk Starbucks.

(3) Setiap kegiatan untuk mensosialisasikan produk Starbucks yang ramah lingkungan sebaiknya dikemas dengan menarik dalam bentuk kata-kata yang lebih sederhana, jelas dan mudah dipahami masyarakat umum agar tidak mengakibatkan kebingunan bagi konsumen yang bisa berefek negatif pada green trust Starbucks. (4) Semua informasi yang diberikan hendaknya mengajak masyarakat untuk memiliki kesadaran, kita semua punya peran penting ntuk merawat bumi menjadi lebih baik lewat hal sederhana seperti memilih bahan-bahan yang ramah lingkungan, seperti mengkonsumsi Starbucks dan menciptakan kesan ada kebanggaan bahwa kita mengambil peran ini untuk merawat bumi. (5) Pentingnya promosi yang mengandung edukasi tentang ramah lingkungan sangat diperlukan untuk menciptakan self monitoring yang semakin tinggi pada setiap kita. Hal ini bisa diperkuat dengan membangun hubungan yang lebih dekat dengan konsumen. Pemasaran ini juga sangat efektif di lingkungan pendidikan dan acara-acara yang erat kaitannya dengan menjaga lingkungan. Dengan strategi yang tepat akan menimbulkan daya tarik konsumen untuk membeli kembali.

\section{DAFTAR PUSTAKA}

Antonetti, Paolo \& Maklan, Stan. (2014). Feelings that Make a Difference: How Guilt and Pride Convince Consumers of the Effectiveness of Sustainable Consumption Choices. Journal Business Ethics 124:117-134 DOI 10.1007/s10551-013-1841-9

Chen, Y. S. (2010). The Driver of Green Brand Equity: Green Brand Image, Green Statisfaction, and Green Trust. Journal of Business Ethics 9 (3): pp: 307-319.

Cheng, J. T., Tracy, J. L., \& Henrich, J. (2010). Pride, personality, and the evolutionary foundations of human social status.Journal of Evolution and Human Behavior: 31(5), 334-347.

Chen, Y. S., \& Chang, C. H. (2012). Enhance green purchase intentions: The roles of green perceived value, green perceived risk, and green trust. Journal of Management Decision, 50(3), 502-520.

Chen, Y. S., \& Chang, C. H. (2013).Towards green trust The influences of green perceived quality, green perceived risk, and green satisfaction. Journal of Management Decision Vol. 51 No. 1,pp.63-82

Dedeoglu, Ayla Ozhan \& Kazabcoglu, Ipek. (2010). The Feelings of Consumer Guilt: A Phenomenological exploration/Vartotojo Kaltes Jausmas: Fenomeno logijos Tyrinejimas. Journal of Business Economics and Management

Kabaday1, Ebru Tümer., Dursun, İnci., Alana, Alev Koçak \& Tugera, Ahmet Tuğrul. (2015). Green purchase intention of young Turkish consumers: Effects of consumer's guilt, self-monitoring and perceived consumer effectiveness. Journal of Procedia - Social and Behavioral Sciences $207: 165$ - 174

So, Yun Kim et al. (2012). Toward a Composite Measure of Green Consumption: An Exploratory Study Using a Korean Sample. Journal of Family and Economic Issues Volume 33, Issue 2, pp 199-214

Vaishnavi, Ganesh \& Thomas, Charlie. (2014). Environmental Behaviour of Consumers visà-vis Customer Relationship, Trust and Loyalty: Some Research Reflections and Organisational Practices. Journal of Business Studies Quarterly, Volume 6, Number 2

Wu, S. I., \& Chen, Y. J. (2014). The Impact of Green Marketing and Perceived Innovation on Purchase Intention for Green Products. International Journal of Marketing Studies. 6 (5), pp: 1918-719. 


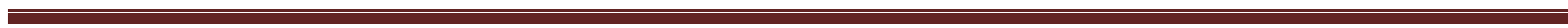
$\cdot$ 